\title{
Laboreal
}

Volume $1 \mathbf{N}^{\circ} 1$ | 2005

Varia

\section{Las dramáticas del uso de si de jóvenes madres trabajadoras : cartografías del trabajo en insospechables territorios}

As dramáticas do uso de si de jovens mães trabalhadoras: cartografias do trabalho em insuspeitáveis territórios

Les dramatiques de l'usage de soi chez de jeunes mères qui travaillent: cartographies du travail en des territoires insoupçonnés Self use dramatics of young working mothers : cartographies of work in unsuspected territories

\section{Suyanna Barker}

\section{(2) OpenEdition}

\section{Journals}

Edición electrónica

URL: http://journals.openedition.org/laboreal/14110

DOI: $10.4000 /$ laboreal. 14110

ISSN: 1646-5237

Editor

Universidade do Porto

Referencia electrónica

Suyanna Barker, «Las dramáticas del uso de si de jóvenes madres trabajadoras : cartografías del trabajo en insospechables territorios », Laboreal [En línea], Volume $1 N^{0} 1$ | 2005, Publicado el 01 diciembre 2005, consultado el 24 septiembre 2020. URL : http://journals.openedition.org/laboreal/ 14110 ; DOI : https://doi.org/10.4000/laboreal.14110

Este documento fue generado automáticamente el 24 septiembre 2020

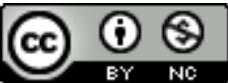

Laboreal está licenciado com uma Licença Creative Commons - Atribuição-NãoComercial 4.0 Internacional. 


\section{Las dramáticas del uso de si de jóvenes madres trabajadoras : cartografías del trabajo en insospechables territorios}

As dramáticas do uso de si de jovens mães trabalhadoras : cartografias do trabalho em insuspeitáveis territórios

Les dramatiques de l'usage de soi chez de jeunes mères qui travaillent: cartographies du travail en des territoires insoupçonnés

Self use dramatics of young working mothers : cartographies of work in unsuspected territories

\section{Suyanna Barker}

\section{REFERENCIA}

Linhales Barker, S. (2005). As Dramáticas do uso de si de jovens mães trabalhadoras : cartografias do trabalho em insuspeitáveis territórios. Tese de Doutoramento. Rio de Janeiro : Escola Nacional de Saúde Pública Sergio Arouca, Fundação Oswaldo Cruz.

\section{NOTA DEL EDITOR}

Manuscrito recibido en : septiembre/2005

Aceptado tras peritage en : septiembre/2005

1 Tesis de doctorado defendida en Escola Nacional de Saúde Pública Sergio Arouca - ENSP da Fundação Oswaldo Cruz en la ciudad de Rio de Janeiro, Brasil en junio de 2005. Contó con la orientación de la Investigadora Jussara Cruz de Brito da ENSP y co-orientación de 
Maria Elizabeth Barros de Barros, Profesora de la Universidade Federal do Espírito Santo y tuvo como objetivo principal transformar para comprender el trabajo de jóvenes madres trabajadoras, residentes en una favela (barrios de chabolas) en la ciudad de Rio de Janeiro.

2 La necesidad de transformar para comprender surgió porque estas mujeres jóvenes, con historias de embarazos y trabajo en la adolescencia, no están reconocidas, ni socialmente, ni por ellas mismas como trabajadoras. En parte esto ocurre debido a la poca edad con la que ingresan en el mercado informal del trabajo. Existen en todo el Brasil cinco millones y medio de niñas y adolescentes, entre cinco y diecisiete años, económicamente activas, estando la mayor concentración de esas trabajadoras entre las adolescentes, que a pesar de tener edad legal para el trabajo, están en su mayoría empleadas en el mercado informal, y sin garantías de la seguridad social y del trabajo. Además, las estadísticas apuntan una inclusión mayor de mujeres en general en el mercado de trabajo, existiendo, sin embargo, un gueto en el servicio doméstico para las mujeres jóvenes, sin calificación formal y que ya tengan por lo menos un hijo. Este cuadro refleja el fenómeno de la feminización de la pobreza en Brasil que hace con que espacios populares denominados favelas (barrios de chabolas) sean habitadas por familias cuyo jefe es la mujer, que empiezan a trabajar antes de completar una formación profesional y consecuentemente se transforman en mano-de-obra barata y flexible capaz de suplir necesidades exploratorias del capitalismo tardío. Esta coyuntura hace con que el trabajo de estas mujeres sea invisible y poco valorado. La falta de reconocimiento y de espacio para comprender la actividad de trabajo de estas jóvenes produce un grupo de trabajadoras que desconoce sus propias habilidades y astucias para lidiar con la pobreza y criar a sus hijos con dignidad. Procurar comprender las actividades de trabajo de estas jóvenes ha necesitado la construcción de un abordaje de pesquisa que transformase lo ya conocido sobre estas mujeres e instituyese nuevas comprensiones sobre sus actividades de trabajo.

3 Este estudio salió de una revisión bibliográfica sobre la situación del trabajo de mujeres, niñas y jóvenes en Brasil y la interpelación de la reproducción en este fenómeno. A continuación, partiendo de los conceptos de modos de subjectivación (Foucault, 1977) y producción de subjetividad (Deleuze \& Guattari, 1987), se formó un marco teórico para la comprensión de la dimensión subjetiva de este acontecimiento. Las suposiciones teóricas de la ergonomía de la actividad situada (Teiger,1998), de la Psicodinámica del trabajo (Dejours, 1999), así como, los conceptos de normas antecedentes, corpo-si y dramáticas del uso de si de la Ergología (Durrive \& Schwartz, 2003) han sido el manantial para el entendimiento de la dimensión subjetiva atravesada por la actividad del trabajo. Para la recogida de los datos empíricos han sido fundamentales las suposiciones de la Clínica de la Actividad desarrollada por Yves Clot (Clot, 2001), en especial en el uso que este hace de la técnica de Instrucción al sosia forjada por Oddone y colaboradores (Clot, 1999). También, de las análisis realizadas por la Clínica de la Actividad, se usó el concepto de actividad impedida como fuente de sufrimiento psíquico.

4 A continuación, se construyó una metodología de pesquisa-intervención basada en los presupuestos del Análisis Institucional francés, en la forma como esta ha sido apropiada en Brasil (Rocha \& Aguiar, 2003). Según el Análisis Institucional, una pesquisaintervención procura producir un diálogo entre teoría y práctica donde no hay la anterioridad de una en comparación con la otra. Como metodología básica se colocó en 
análisis el sentido instituido sobre el trabajo y la maternidad y, activamente, se marcaron los movimientos, las diferencias y las posibilidades de otros sentidos. También han sido elegidas para este estudio técnicas de investigación utilizadas en las ciencias humanas y sociales, en especial aquellas en que los sujetos de la pesquisa actúan activamente en el proceso de producción de conocimiento (Becker, 1993; Certeau, 1994). Para la ejecución de la pesquisa han sido realizados grupos de discusión semanales, por un período de seis meses, junto a un Centro Comunitario en una de las favelas (barrios de chabolas) de la ciudad de Rio de Janeiro. Para participar en estos encuentros han sido invitadas mujeres jóvenes con historia de embarazo y trabajo en la adolescencia y para cada encuentro el grupo produjo material gráfico y discursivo que fue registrado y usado posteriormente en el análisis de los datos. La pesquisa contó con cuatro fases distintas de ejecución, desde la negociación con el centro comunitario hasta las entrevistas individuales realizadas al final del proceso. Además de esta tesis, estos encuentros también han producido una cartilla, elaborada por las jóvenes y orientada hacia otras mujeres que estén pasando por las mismas experiencias de vida y trabajo. Este material sintetiza las discusiones efectuadas en el grupo durante los meses de pesquisa-intervención.

5 La acción de transformar para comprender el trabajo, emprendida por el camino metodológico arriba descrito efectuó una ampliación en el entendimiento sobre las actividades realizadas por las jóvenes madres, así como propició que estas se considerasen como sujetos con competencia para hablar de sus actividades de trabajo. De esa forma ha sido posible agregar un buen número de historias, contadas por las jóvenes y discutidas en el grupo de pesquisa, donde se ha ido explicitando los debates de valores efectuados en el curso de las diversas actividades que realizan en sus vidas, es decir, sus dramáticas del uso de si. La composición que se realizó al disponerse el contexto del trabajo precoz femenino y las herramientas conceptuales elegidas para dialogar con las historias singulares de las jóvenes madres trabajadoras han producido seis pistas-resultados de suma importancia para el análisis de las cuestiones de salud y trabajo de jóvenes trabajadoras, son ellas :

6 (1) Se constató que, entre mujeres jóvenes, moradoras de espacios populares y con historia de embarazo en la adolescencia, la discusión de la composición salud y trabajo no aparece de forma espontánea, necesitando una metodología de intervención que produzca lenguaje sobre el trabajo que ellas ejecutan y sus efectos sobre la salud. Al final de la intervención, se consiguió notar actividades de trabajo donde ellas parecían no existir y, así, se cartografió el trabajo en insospechables territorios. Para eso, fue necesario tanto ampliar la noción de trabajo y entender su carácter enigmático cuanto considerar que existen modos sexuados de vivir y trabajar.

(2) Se observó que la constitución del grupo "A Favor Delas" (A favor de Ellas), que ocurrió durante el proceso de pesquisa-intervención, propició el desvendar del carácter colectivo del trabajo de las jóvenes madres y la importancia de esa colectividad para el enfrentamiento de los más diversos retos experimentados por ellas. Se empezó a cartografiar, entonces, las Entidades Colectivas Relativamente Pertinentes (Durrive \& Schwartz, 2003) en medios no tradicionalmente pensados como ambientes de trabajo. Al ampliarse el concepto de ECRP para esos nuevos territorios, se entendió que el trabajo precoz femenino ocurre en red con otras mujeres, en el ámbito doméstico y productivo, desde muy pronto en la vida de las niñas de clase popular, pero no se 
configura como un colectivo único y constante, pero sí como una lógica de trabajo, sucesivamente plural, pero siempre relativamente pertinente.

(3) Se comprobó que lo real de la actividad de trabajo de mujeres jóvenes, jefes de familia, impone una jornada de trabajo ampliada que les dificulta el acceso a la educación formal y a cursillos de calificación profesional. Al mismo tiempo, propicia el aprendizaje de una serie de habilidades y un actuar en competencia (Durrive \& Schwartz, 2003) que aún no gozan de reconocimiento social, aunque sean extremadamente útiles para el actual mundo de trabajo. El reconocimiento de ese patrimonio acumulado informalmente debe de estar en la base de cualquier iniciativa que busque dar una oportunidad en el trabajo digno para las clases populares.

9 (4) Se identificó la expresión del trabajo inmaterial (manipulación del afecto en las actividades de cuidar y atender a personas) para las mujeres pobres tanto en las actividades de reproducción social como en las actividades ligadas al trabajo descalificado, típico de la trabajadora joven de las camadas populares. Se abrió, así, la posibilidad de ampliar la noción de trabajo inmaterial más allá de aquél relacionado apenas con las actividades intelectualizadas. Esa ampliación puede ser el marco conceptual para entenderse un trabajo tan difícil de mensurar, es decir, cuidar de las personas y hacer la reproducción social.

10 (5) Se notó que la reproducción tiene un valor singular para jóvenes residentes en espacios populares y remite para la posibilidad de planear e invertir en el futuro. Delante de la certeza de que el retraso de la reproducción no implicará necesariamente movilidad social, mujeres jóvenes hacen uso de la maternidad como forma de conquista de autonomía y direccionamiento de la vida adulta. En este sentido, el ritual reproductivo en mucho se asemeja al proceso de reconocimiento social forjado por la posibilidad de trabajo productivo digno y ejecutado como profesión.

11 (6) Se observó que los procesos de impedimento de las actividades de trabajo, causados por la falta de reconocimiento social de las habilidades aprendidas en el ámbito doméstico, son fuente de sufrimiento, pues están asociados a un margen de maniobra restricta que dificulta los procesos de resingularización de las experiencias de trabajo. El sufrimiento adviene más de aquello que no puede ser desarrollado que de las dificultades inherentes a una actividad de trabajo.

\section{BIBLIOGRAFÍA}

Becker, H.S. (1993). Método de pesquisa em ciências sociais. São Paulo : Hucitec.

Certeau, M. (1994). A Invenção do Cotidiano. Petrópolis : Editora Vozes.

Clot, Y. (1999). I. Oddone : les instruments de l'action. Territoires du travail, 3.

Clot, Y. (2001). Clinique du travail, clinique du réel. Le journal des psychologues, 185, 48-51.

Dejours, C. (1999). A Banalização da Injustiça Social. Rio de Janeiro : Editora FGV. 
Deleuze, G. \& Guattari, F. (1987). A Thousand Plateaus : capitalism \& schizophrenia. Minneapolis : University of Minnesota Press.

Durrive, L. \& Schwartz, Y. (2003). Travail et Ergologie : entretiens sur l'activité humaine. Toulouse : Octarès Éditions.

Foucault, M. (1977). Discipline and punish : the birth of the prison. New York : Vintage Books.

Rocha. M.L. \& Aguiar, K.F. (2003). Pesquisa-intervenção e a Produção de Novas Análises. Psicologia Ciência e Profissão, Brasília - CFP, 2003, 4, 24-33.

Teiger, C. (1998). Las representaciones funcionales en el trabajo. Ergonomía : conceptos y métodos. Madri : Editorial Complutense.

\section{AUTOR}

\section{SUYANNA BARKER}

Universidade do Estado do Rio de Janeiro, Brasil, Rua Aiurú, \# 73/201, Humaitá, Rio de Janeiro, RJ, CEP : 22261-110, Brasil

suyanna@uerj.br 